\title{
O PROGRAMA NACIONAL ESCOLA DE GESTORES DA EDUCAÇÃO BÁSICA NA UNIVERSIDADE FEDERAL DE VIÇOSA-MG: IMPASSES E PERSPECTIVAS NA VISÃO DO GESTOR
}

\author{
THE NATIONAL PROGRAM SCHOOL MANAGERS OF BASIC \\ EDUCATION AT THE UNIVERSIDADE FEDERAL DE \\ VIÇOSA-MG: IMPASSES AND PERSPECTIVES IN THE \\ MANAGER'S POINT OF VIEW
}

EL PROGRAMA NACIONAL ESCUELA DE GESTORES EN LA
EDUCACIÓN BÁSICA EN LA UNIVERSIDADE FEDERAL DE
VIÇOSA-MG: Y PERSPECTIVAS EN LA VISIÓN DEL GESTOR

\author{
Valdirene Eliane Bailon de Souza ${ }^{1}$ \\ Edgar Pereira Coelho ${ }^{1}$ \\ Rita Márcia Andrade Vaz de Mello ${ }^{1}$
}

\begin{abstract}
Resumo O presente artigo analisa os principais impasses e perspectivas da formação continuada de Gestores Escolares e, ao mesmo tempo se essa formação a distância no âmbito do Programa Nacional Escola de Gestores da Educação Básica (PNEGEB), ofertado pela Universidade Federal de Viçosa-MG, contribuiu para a prática pedagógica desse profissional. Para responder aos questionamentos da pesquisa, adotou-se como perspectiva metodológica a abordagem qualitativa. Foram utilizados como instrumentos para a coleta de dados: análise teórico-bibliográfica, análise da matriz curricular e dos documentos oficiais do PNEGEB, análise de dez TCCs dos cursistas/gestores da Zona da Mata Mineira, período 2013-2014, e aplicação de cinco questionários aos gestores já egressos pelo programa. Os resultados apontaram situações problema importantes, onde fica explícito que a educação brasileira sofre com os mais diversos problemas e carências de origem socioeconômica e política. Indicaram ainda que os gestores entenderam que essa formação e a prática reflexiva foram fundamentais para uma mudança e uma consequente melhoria da atuação profis-
\end{abstract}

\footnotetext{
${ }^{1}$ Universidade Federal de Viçosa (UFV), Viçosa/MG - Brasil.
} 
sional. Ademais, as análises mostraram que essa formação continuada foi relevante em sua essência diante da prática pedagógica dos gestores.

Palavras-chave: Programa Nacional Escola de Gestores; Gestão Democrática; FormaÇão Continuada; EducaÇ̃̃o a Distância.

Abstract This article analyzes the main problems and prospects of continuing education of School Managers, and at the same time this distance training under the National School Program Managers of Basic Education (PNEGEB), offered by the Universidade Federal de Viçosa-MG, contributed to the managers' pedagogical practice. To answer the research questions it is adopted as a methodological approach to qualitative approach. The instruments used to achieve the purpose of the study were: theoretical and literature review; analysis of curriculum and official documents of PNEGEB; ten TCCs analysis of students/ managers of the Zona da Mata Mineira, during the period 2013-2014, besides the application of five questionnaire to graduate managers of the program. The TCCs showed relevant problems, where it is clear that the Brazilian education suffers from various problems and shortcomings of socioeconomic background and politics. The survey results indicated that managers understand that such training and reflective practice were fundamental for a change and a consequent improvement of professional performance. Moreover, the analysis showed that continued education was relevant in its essence on the managers' pedagogical practice.

Key-words: National Program School Managers; Democratic management; Continued eduCATION; Distance EduCATion.

RESUMEN El presente artículo analiza los principales dificultades y perspectivas de formación continua de Gestores Escolares y, mismo tiempo la formación a distância en el ámbito del Programa Nacional de Escuela de Gestores de Educación Básica (PNEGEB), ofrecido por la Universidade Federal Viçosa - MG, contribuye para la práctica pedagógica de ese profesional. Para responder a las cuestiones de la investigación, se adoptó una perspectiva metodológica el abordaje desde punto de vista cualitativo. Se utilizaron como instrumentos para colecta de datos: análisis teórico bibliográfico, análisis de matriz circular y los documentos oficiales de análisis de PNEGEB; análisis de 10 TCCs de los inspectores de la Zona de Mata mineira, en el período 2013-2014, y realización de 5 encuestas a los gestores graduados en el programa. Los resultados apuntaron situaciones y problemas importantes, dónde queda explícito que la educación brasileña sufre con los más diversos problemas y carencias de orden socioeconómico y político. Indicaron que los gestores entienden que esa formación es la práctica reflexiva y que fueron fundamentales para un cambio y una consecuente mejoría de la actuación profesional. Además, los análisis demuestran que esa formación continuo fue relevante en su esencia delante de la práctica pedagógica de los gestores. Palabras clave: Programa Nacional Escuela de Gestores; Gestión Democrática; ForMación Continua; EdUCACIÓn a Distância. 


\section{INTRODUÇÃo}

A atuação do gestor escolar na contemporaneidade ganha visibilidade com as novas responsabilidades que chegam à escola, principalmente com as questões administrativas e pedagógicas. Nesse viés, torna-se relevante a busca pelo entendimento do papel desempenhado pelo gestor e da sua visão diante da sua realidade escolar. Assim, o objetivo desta pesquisa é analisar os principais impasses e perspectivas da formação continuada de Gestores Escolares e, ao mesmo tempo, se essa formação a distância no âmbito do Programa Nacional Escola de Gestores da Educação Básica (PNEGEB), contribuiu para a prática pedagógica desse profissional.

No que tange às políticas educacionais de formação voltadas para esse profissional, apresentamos o PNEGEB, que foi implementado em caráter experimental, em 2005, sob a coordenação do INEP. O seu principal objetivo é oferecer formação a gestores de escolas públicas municipais/estaduais a partir de cursos na modalidade de Educação a Distância. Esse programa, como outros da área educacional, surgiu na gestão do presidente Luiz Inácio Lula da Silva (2003-2010), como uma das ações de implementação de políticas para educação.

Com base na literatura sobre a temática gestão, cabe ressaltar que os gestores, com experiência ou não, compartilham das mesmas dificuldades no dia a dia de trabalho, como: falta de professores, número reduzido de funcionários, violência contra a instituição, falta de recursos financeiros, dificuldade do trabalho coletivo entre comunidade e membros da escola, entre outros. Contudo, não se compreende ainda como esses gestores atenuam as dificuldades surgidas no cotidiano do trabalho e as enfrentam com mais segurança por meio da formação continuada.

Partindo dessa premissa, alguns questionamentos emergem para o direcionamento desta pesquisa: Quais as contribuições do PNEGEB para a prática profissional desses gestores escolares? Quais os desafios que marcam a atuação desses gestores? O PNEGEB atende às necessidades reais dos gestores? Quais dificuldades encontradas no ambiente escolar são retratadas no TCC?

Nessa ótica, a presente pesquisa dedicou-se ao estudo do PNEGEB, ${ }^{1}$ especificamente o de Gestão escolar ofertado pela Universidade Federal de Viçosa (UFV) - Departamento de Educação/Campus Viçosa-MG. ${ }^{2}$ Oferecido a distância, o curso teve início na instituição em setembro de 2008, com o mesmo objetivo citado, por se tratar de um programa em âmbito nacional, porém, voltado para a formação continuada de gestores de escolas públicas

1 No PNEGEB, são disponibilizadas 400 vagas, sendo que a carga horária do curso é de 400 horas, totalizando um período de três semestres, na modalidade a distância. O total de gestores ingressos na UFV, período 2013-2014, foi de 400 cursistas, porém, só 288 concluíram o curso em Gestão Escolar. Início da turma: agosto de 2013 e conclusão em dezembro de 2014.

2 A Universidade Federal de Viçosa possui três campi: Viçosa, Rio Paranaíba e Florestal para o desenvolvimento de suas atividades de ensino, pesquisa e extensão. Somente o Campus de Viçosa oferece o curso de Pós-Graduação Lato Sensu em Gestão Escolar por meio da UNDIME/MG. 
da Zona da Mata Mineira. ${ }^{3}$ Desse modo, os resultados e as discussões deste estudo estão fundamentados teoricamente em autores como Cury (1997), Freitas (2007), Nóvoa (2009), Libâneo (2009), Luck (2011), e Moran (2015).

No espaço universitário, entende-se a formação continuada como uma das funções das universidades em cooperação com as Secretarias de Educação ou com as escolas públicas do município. Diante disso, as Secretarias de Educação vêm destacando a parceria com os sistemas de ensino públicos, principalmente, pela compreensão e reconhecimento de que as Instituições Federais de Ensino Superior (IFES) são um lócus de formação e produção de conhecimento, promovendo a formação de gestores educacionais para atuar na perspectiva da gestão democrática e da educação inclusiva.

Salienta-se, nesse contexto, que esta pesquisa é norteada pelo que Mainardes (2011) enfatiza sobre a avaliação da política educacional, os seus efeitos, efetividade e os seus êxitos. Tem como fio condutor para a análise a possibilidade de considerar as políticas educacionais em suas condições reais, de justiça e igualdade, ponderando seus impactos nas interações com as desigualdades existentes no meio onde é aplicada. Para o autor, a pesquisa a respeito de políticas educacionais vem a cada dia configurando-se como um campo distinto de investigação e em permanente busca de consolidação.

Além desse aspecto, autores como Paro (2008) e Fernandes (2015) evidenciam a necessidade de pesquisas que priorizem a explicitação dos problemas do cotidiano escolar por intermédio do gestor. Por esse, e outros aspectos já citados, acredita-se que o desenvolvimento deste artigo seja relevante, já que traz o olhar do gestor para o interior da escola e da sua própria formação.

\section{Algumas ConsideraÇões SOBRe a GeStão escolar democrática no ambien- TE ESCOLAR}

Para dar início a este tópico, é necessário exemplificar que o conceito de gestão significa tomada de decisões, organização e direção. Relaciona-se com a atividade de impulsionar uma organização a atingir seus objetivos e cumprir suas responsabilidades.

Segundo Fernandes (2015), a preocupação com a formação e a capacitação de gestores escolares, como uma via para melhorar a qualidade do ensino e fortalecer a gestão democrática, fez que o tema entrasse para a agenda política apenas no final dos anos de 1990. Nesse sentido, o Programa de Capacitação a Distância para Gestores Escolares (PROGES$\mathrm{TÃO})$ foi a primeira iniciativa de maior destaque, sendo proposto pelo Conselho Nacional de Secretários de Educação (CONSED), em parceria com Secretarias de Educação e apoio de diversas fundações. Segundo a mesma autora, foi somente nos anos 2000 que o termo gestão intensificou-se por meio da implementação de novas políticas públicas, do controle

3 A Zona da Mata Mineira é uma das doze mesorregiões do Estado brasileiro de Minas Gerais, formada por 142 municípios agrupados em sete microrregiões. Situa-se na porção sudeste do Estado, próxima à divisa dos Estados do Rio de Janeiro e do Espírito Santo. Disponível em: $<$ http://cidades.ibge.gov.br/painel/historico.php?codmun=316400>. Acesso em: 25 fev. 2016.

54 Comunicações | Piracicaba | v. 24 | n. 3 | p. 51-65 | setembro-dezembro 2017 
governamental e do aumento da responsabilidade do gestor escolar, que assume tarefas focadas em metas e desempenho, tornando-se um "gerente" para maximizar os resultados e tornar a escola mais eficiente.

Assim, no ano de 2003, o governo federal deu continuidade a vários programas voltados para a melhoria da qualidade da educação básica, pois as avaliações realizadas vinham apontando debilidades na educação pública. Entre os programas, destacam-se alguns voltados para a gestão escolar, como: Plano de Desenvolvimento da Escola (PDE), Fundo de Desenvolvimento da Escola (FUNDESCOLA), Programa Dinheiro Direto na Escola (PDDE) e o Programa Nacional Escola de Gestores da Educação Básica (PNEGEB). O PNEGEB, em 2007, passou a compor o Plano de Desenvolvimento da Educação (PDE) e tinha como objetivo contribuir para a formação efetiva de gestores educacionais da escola pública, dispondo de elementos teórico-práticos que viabilizassem uma educação escolar básica com qualidade social e na perspectiva da inclusão.

Nesse sentido, no contexto educacional, gestão é uma expressão que ganhou espaço ao acompanhar uma mudança de paradigma no encaminhamento das questões dessa área. Em linhas gerais, é caracterizada pelo reconhecimento da importância da participação consciente e esclarecida das pessoas nas decisões sobre a orientação e planejamento do seu trabalho (LUCK, 2011). O conceito de gestão está associado ao fortalecimento da democratização do processo pedagógico à participação responsável de todos nas decisões necessárias e na sua efetivação, mediante um compromisso coletivo com resultados educacionais cada vez mais significativos. Sobre esse tema:

\footnotetext{
Conforme afirmado em trabalho conjunto entre UNESCO e MEC, "o diretor/ gestor é cada vez mais obrigado a levar em consideração a evolução da ideia de democracia, que conduz o conjunto de professores, e mesmo os agentes locais, à maior participação, à maior implicação nas tomadas de decisão. A essa exigência estaria vinculada a necessidade de interpenetração da dimensão pedagógica e política, na questão administrativa. Em consequência, os antigos fundamentos de administração educacional seriam insuficientes, embora importantes, para orientar o trabalho do dirigente educacional com essa nova dimensão (LUCK, 2011, p. 37).
}

Percebe-se, que a gestão escolar democrática, que se desenvolve e se realiza por meio da efetiva participação comprometida de todos, precisa basear-se numa definição abrangente do conceito de união, num compromisso de construir uma comunidade que é tanto da escola quanto da sociedade onde ela se insere.

Com base nessa concepção, entende-se que a democratização começa no interior da escola por meio da criação de espaços nos quais professores, funcionários, alunos, pais de alunos e outros membros da comunidade local podem discutir com discernimento o cotidiano escolar. A função da escola é formar indivíduos críticos, criativos e participativos, com condições para participar do mundo do trabalho e de lutar por uma melhor educação no país. Sobre a administração democrática: 
A possibilidade de uma administração democrática no sentido de sua articulação, na forma e no conteúdo com os interesses da sociedade como um todo, tem a ver com os fins e a natureza da coisa administrada. No caso da Administração Escolar, sua especificidade deriva, pois: a) dos objetivos que se buscam alcançar com a escola; b) da natureza do processo que envolve essa busca. Esses dois aspectos não estão de modo nenhum desvinculados do outro. A apropriação do saber e o desenvolvimento da consciência crítica, com objetivos de uma educação transformadora, determinam, [...] a própria natureza peculiar do processo pedagógico escolar; ou seja, esse processo não se constitui em mera diferenciação do processo de produção material que tem lugar na empresa, mas deriva sua especificidade de objetivos (educacionais) peculiares (PARO, 2008, p. 15).

A democratização da gestão escolar implica tentar envolver todos os segmentos da escola num processo pedagógico. Nesse sentido, entender essa gestão em toda a sua complexidade implica considerar a escola como espaço pedagógico tenso e contraditório, com diferentes concepções de mundo, de homem e de sociedade distintos e em disputas. "[...] a escola e os processos de sua gestão não devem ser vistos como entes autônomos e, muito menos, como espaços de mera reprodução das relações sociais mais amplas" (DOURADO, 2008, p. 18).

Mesmo com os avanços, muitas escolas ainda apresentam caráter autoritário. Na sociedade moderna, não cabe mais o papel de um gestor centralizador. Desse modo, a gestão democrática, com participação efetiva em todas as decisões a serem tomadas na escola, torna-se o caminho em busca de uma educação mais próspera, onde todos os participantes do contexto escolar podem emitir suas opiniões sem medo de represálias.

\section{Procedimentos metodológicos}

Metodologicamente, o artigo em exposição retrata fragmentos da pesquisa de mestrado que centrou no estudo de um programa de formação continuada para gestores em uma instituição federal. Ao buscar compreender os percursos vinculados a essa formação e a contribuição desta para a prática profissional, adotou-se como abordagem metodológica a pesquisa qualitativa. ${ }^{4}$

Nesse sentido, a primeira etapa foi análise documental e bibliográfica, que viabilizou informações pertinentes para a pesquisa. Na segunda etapa, realizou-se um levantamento de TCCs $^{5}$ dos cursistas do período de 2013-2014, em busca de compreender os principais desafios do ambiente de trabalho. A escolha temporal por esse período deu-se pelo fato de serem os TCCs mais recentes produzidos pelos gestores no curso. Desse modo, analisar e refletir a respeito dos trabalhos atuais poderá ajudar a compreender mais acerca dos impasses e perspectivas dos gestores na contemporaneidade.

\footnotetext{
4 Segundo Gomes (2012), essa metodologia prima pela leitura, pela interpretação, pela aproximação das possíveis e diferentes configurações que um problema de investigação assume, e as dimensões possíveis de enfoque, quando se pensa na complexidade.

5 O total de TCCs da última turma concluinte do curso na UFV, período de 2013-2014, foi de 72 trabalhos, sendo que, estes poderiam ser elaborados em grupos de três a cinco integrantes do mesmo município.
} 
A compreensão desses desafios foi possível porque a proposta de construção do TCC orientava que os temas a serem trabalhados, em alguma medida, devessem abordar as situações problemas vivenciadas no ambiente de trabalho. A partir disso, o trabalho final consistia na criação de um projeto de intervenção com estreita vinculação ao Projeto Político Pedagógico, realizado pelo próprio cursista dentro da sua realidade escolar.

Sintetizando esse processo, durante a análise dos TCCs foram escolhidos dez trabalhos para a pesquisa, selecionando-se dois do mesmo assunto, no sentido de compreender como gestores de ambientes escolares distintos da Zona da Mata Mineira retrataram sobre a mesma questão. A escolha por essa quantidade de trabalhos ocorreu por ser uma quantidade satisfatória para um estudo mais consistente e detalhado dos trabalhos, e todos foram lidos e analisados na íntegra.

A terceira etapa teve o objetivo de complementar a pesquisa e a discussão sobre o efeito dessa formação para a atuação do gestor. Foram aplicados questionários a cinco gestores já egressos pelo programa. Desse modo, o questionário ${ }^{6}$ foi composto por dez questões, sendo duas objetivas com a possibilidade de marcar somente uma alternativa e oito subjetivas com espaços livres para os registros.

Todos os gestores egressos que participaram da pesquisa atuavam em escolas públicas municipais de Viçosa-MG, sendo três localizadas no centro e duas em bairros distintos do município. A proposta de aplicação dos questionários teve por objetivo compreender mais sobre o próprio curso na UFV. Dessa forma, essas questões tiveram a finalidade de explicitar como ocorreu o processo de construção dos TCCs, suas dificuldades no ensino a distância, desafios que marcaram a atuação como gestores e, confirmar ou contrapor se os objetivos do programa contribuíram para mudanças na gestão escolar, a partir da sua prática pedagógica.

Para a aplicação dos questionários, inicialmente foi feito contato por telefone com várias escolas do município, no sentido de saber se os respectivos gestores tinham realizado a formação específica em gestão escolar na UFV. Caso a resposta fosse positiva e houvesse disponibilidade de participar e contribuir para a pesquisa, o dia e o horário eram marcados para o contato entre gestor e pesquisador. Após informar sobre todo o procedimento da pesquisa, um questionário e termo de consentimento era entregue ao gestor e, uma nova data era marcada para recolher os respectivos documentos.

A metodologia utilizada nessa fase foi o método de análise de conteúdo que, de acordo com Gomes (2012), deve ser feita utilizando as seguintes etapas interligadas: pré-análise, descrição analítica dos dados e interpretação referencial. Relacionada a essa mesma questão, Ludke e André (1986) salientam que, analisar os dados obtidos durante uma pesquisa de cunho qualitativo é uma tarefa imprescindível e requer muitos cuidados por parte do pesquisador.

Cabe ressaltar que não houve identificação nominal dos gestores, sendo que o projeto de pesquisa foi submetido à análise do Comitê de Ética em Pesquisa com Seres Humanos

6 Ao contrário dos TCCs que apresentaram integrantes de municípios distintos da Zona da Mata Mineira, os gestores participantes do questionário foram somente do município de Viçosa-MG. 
da UFV, tendo o parecer favorável à aplicação dos questionários e análise dos TCCs. Em linhas gerais, este estudo primou por um caminho investigativo, em que os instrumentos metodológicos escolhidos serviram de apoio para o levantamento dos dados.

\section{RESUlTADOS E DISCUSSÕES}

Algumas considerações e reflexões a partir da Análise dos TCCs produzidos na UFV (Período 2013-2014)

Apresenta-se, a seguir, no Quadro 1, os principais trabalhos científicos analisados na íntegra. A escolha desses TCCs ocorreu a partir de uma primeira leitura, a fim de ressaltar os aspectos diversos e importantes sobre problemas provenientes da escola básica pública. Assim, as categorias que mais se destacaram, entre o total de 72 trabalhos, foram: Inclusão, Gestão Democrática, Indisciplina, Tecnologias e Relação Família/Escola.

Quadro 1 - Categorias e temas dos TCCs

\begin{tabular}{|c|c|}
\hline Categorias & Temas dos TCCs \\
\hline Inclusão & $\begin{array}{l}\text { A) Inclusão Escolar: entre avanços e impasses } \\
\text { B) Educação Inclusiva no contexto escolar }\end{array}$ \\
\hline Gestão Democrática & $\begin{array}{l}\text { C) Gestão Escolar Democrática: um estudo de caso em uma } \\
\text { escola pública de MG } \\
\text { D) Gestão Democrática na escola: princípios, significados e } \\
\text { dimensões }\end{array}$ \\
\hline Indisciplina & $\begin{array}{l}\text { E) Indisciplina em sala de aula: uma visão dos professores das } \\
\text { séries iniciais do Ensino Fundamental de escolas municipais } \\
\text { F) Indisciplina na escola: influência de fatores internos ou } \\
\text { externos? }\end{array}$ \\
\hline Tecnologias & $\begin{array}{l}\text { G) As Tecnologias de Informação e Comunicação (TICs) na } \\
\text { Perspectiva de uma Escola Estadual Mineira } \\
\\
\text { H) A Inclusão das TIC no Processo de Ensino Aprendizagem de } \\
\text { uma Escola Estadual de MG }\end{array}$ \\
\hline Relação Família/Escola & $\begin{array}{l}\text { I) Desafios que permeiam as relações entre escola e família no } \\
\text { cotidiano escolar } \\
\text { J) Como a relação família/escola contribui para o sucesso ou o } \\
\text { fracasso escolar dos estudantes }\end{array}$ \\
\hline
\end{tabular}

Fonte: Dados organizados pela pesquisadora. 
Percebeu-se, nas análises dos trabalhos, que muitos dos cursistas/gestores demonstraram preocupação com as situações que envolvem as questões pedagógicas da escola. Porém, em um único trabalho foram abordados vários assuntos, não focando a principal temática de pesquisa. Essa questão pode estar relacionada ao fato de a construção do TCC ser em grupo, e cada cursista ter escrito uma parte do trabalho, seja pelo fato de ser uma formação continuada em serviço, ou pelo profissional não ter tempo disponível para se dedicar mais profundamente ao estudo.

Observou-se, também, que os temas trabalhados pelos cursistas tiveram origem tanto dentro como fora da escola. Os conflitos gerados por meios extraescolares apresentaram raízes nos problemas sociais, de sobrevivência, de qualidade de vida, de relações familiares. Já no interior da escola, foram elencados os aspectos como a indisciplina, o processo de inclusão, dificuldades em relação à gestão democrática e o uso das tecnologias, o desinteresse do aluno, entre outros aspectos.

Pretendeu-se, ao analisar dois TCCs por categoria, observar como os cursistas trabalharam a mesma temática em contextos escolares diferentes. Entre as cinco temáticas citadas, a única categoria que não se assemelhou na análise dos trabalhos foi o da Inclusão. Por mais que os dois trabalhos abordassem a mesma questão, o primeiro realizou um Estado da Arte acerca da inclusão escolar no Brasil, não focando a temática na realidade escolar. Já o segundo teve como proposta uma pesquisa de campo em uma escola municipal de Minas Gerais, salientando a importância da escola, família e sociedade no processo de inclusão dentro do ambiente escolar. Para a realização deste, colocou-se em prática a pesquisa-ação ou o diagnóstico escolar proposto pelo curso Escola de Gestores.

Em geral, os trabalhos sobre Gestão Democrática se assemelharam ao trazer que essa gestão só é possível com o envolvimento de todos os sujeitos que compõem a comunidade educativa. Já na categoria Indisciplina, ambos os trabalhos afirmaram que o mal comportamento do aluno está relacionado às questões externas ligadas aos fatores sociais e, internas, relacionadas à cultura da própria escola. Sobre as Tecnologias, os dois trabalhos ressaltaram que as escolas pesquisadas são equipadas com computadores. Porém, não há profissionais especializados em informática para dar suporte aos alunos e professores. E, por fim, na categoria Família/Escola, os trabalhos elencaram que só será possível o sucesso escolar do aluno se houver um envolvimento afetivo entre comunidade escolar e família.

Assim, as temáticas apresentadas pelos cursistas/gestores, com exceção de um tema da categoria Inclusão, vieram, de alguma forma, abordar as situações problemas do ambiente de trabalho. Desse modo, revelaram nos TCCs situações problemas importantes, onde fica explícito que a educação brasileira sofre com os mais diversos problemas e carências de origem socioeconômica e política. Dessa maneira, os temas trabalhados extrapolam as competências e possibilidades de solução imediata no âmbito da escola. Isso significa que, ainda que os problemas sejam solucionados, a longo prazo surgirão outros. Com isso, surge a necessidade de uma formação constante, para qualquer profissional, em especial da área educacional. 


\section{EXPERIÊNCIAS COMPARTILHADAS: DIÁLOGO COM OS GESTORES SOBRE O PNEGEB}

Para iniciar essa etapa, é imprescindível relatar que essa formação específica se torna um desafio imposto às políticas educacionais de formação continuada para essa categoria. Conforme a proposta do programa, o público-alvo é o de profissionais que atuam em escolas e municípios com Índice de Desenvolvimento da Educação Básica (IDEB) abaixo da média nacional.

Dessa maneira, ressalta-se que, independente do IDEB da escola ou município, o gestor escolar necessita de uma formação específica, visto que sua rotina está cada vez mais complexa. Esse profissional na contemporaneidade necessita lidar com várias questões, como do espaço escolar, dos recursos financeiros, das relações interpessoais com funcionários, professores, famílias e também da aprendizagem dos alunos. Tudo isso com um objetivo maior, que se não é novo, ganhou uma importância que parecia um pouco esquecida nos últimos tempos: o processo de ensino-aprendizagem da escola (LUCK, 2011).

Dando início à análise do questionário, os gestores foram questionados como se deu o processo de escolha do tema a ser trabalhado no TCC, uma vez que, conforme a proposta do curso, essa seleção deveria partir de uma observação da sua realidade escolar.

Pontuou-se que todos os gestores realizaram observações das relações escolares, para então elaborarem a redação do trabalho final. A partir disso, elencaram situações importantes, como: Cotidiano Escolar; Recreio; Formação Continuada; Relação Família/Escola e Projeto Político Pedagógico (PPP). Para Libâneo (2009, p. 28), a observação e o diagnóstico da realidade escolar envolvem uma "busca de informações reais e atualizadas, que permitem identificar as dificuldades existentes e as causas que as originaram”. Contudo, esse mesmo autor apresenta que a apropriação desses dados é necessária, mas isto não quer dizer que se realizou o diagnóstico da realidade. Isso porque ele é mais complexo que os dados quantitativos, pois envolve situações de vida como condição econômica, social, religiosa, entre outros.

Ao indagar aos gestores como a sala ambiente Projeto Vivencial ${ }^{7}$ contribuiu para a elaboração do TCC, todos evidenciaram a importância desse ambiente para a construção do trabalho final, propiciando reflexões acerca da prática. Nota-se que as contribuições foram em relação às referências bibliográficas, orientações sobre normas da ABNT, discussões acerca da gestão democrática e construção do trabalho final por etapas. Para Moran (2015), os cursos que dão suporte em relação à orientação têm menos evasão, e dão muita ênfase ao atendimento do aluno e à criação de vínculos afetivos, mesmo que esses sejam criados por meio da $\mathrm{EaD}$.

Outro ponto pertinente levantado na análise é o questionamento sobre os desafios escolares que marcaram a atuação desse gestor e quais foram retratados no TCC. Segundo os

\footnotetext{
7 A atividade central, nessa sala, consiste na formulação e desenvolvimento de um projeto de intervenção vinculado ao Projeto Político-Pedagógico (PPP) da escola, assumido como mecanismo fundamental para a realização da gestão democrática na educação, e na escola. O trabalho do cursista nessa Sala Ambiente se desenvolverá desde o início do curso, articulando-se com as demais salas e culminará no TCC (BRASIL, 2009).
} 
registros, muitos são os desafios a serem enfrentados na gestão frente ao contexto em que a escola e a educação estão inseridas na atualidade. Para esses gestores, de alguma forma, os desafios acabam afetando a todos os envolvidos no processo educativo.

Nesse interim, notou-se, nos relatos, principalmente de um gestor, a necessidade de reflexão e participação de todos segmentos no ambiente de trabalho. Desse modo, a gestão democrática surge como uma poderosa ferramenta. Para Lima (2001), com a participação de todos que compõem a comunidade escolar nas decisões da escola, é possível construir um espaço de diálogo, discussão, troca de ideias, valores e até soluções para os possíveis problemas.

Encaminhando para a questão seguinte do questionário, de acordo com Gatti (2010), a formação continuada promove algumas mudanças no trabalho do educador ou gestor. Posto isso, essa temática foi direcionada aos gestores, questionando se essa formação específica em Gestão Escolar surtiu efeito para as necessidades imediatas ou, a longo prazo, no seu ambiente de trabalho.

Pode se descrever, com base no que foi exposto, que todos trouxeram de forma positiva a contribuição dessa formação para o seu trabalho. Entretanto, um gestor relatou que essa formação sanou dúvidas imediatas, mas que as problematizações e discussões do curso poderão trazer também resultados que irão sobressair na sua carreira futuramente.

Para Nóvoa (2009), a formação continuada deve estar articulada com o desempenho profissional dos professores, tomando as escolas como lugares de referência. Trata-se de um objetivo que só adquire credibilidade se os programas de formação se estruturarem em torno de problemas e de projetos de ação e não em torno de conteúdos acadêmicos. Para o autor, as mudanças por meio da formação continuada muitas vezes não são automáticas. Sendo assim, não se pode esperar que um curso de formação continuada tenha efeito imediato sobre a prática dos gestores, pois a mudança é um processo que ocorre com o tempo e depende fundamentalmente da reflexão.

Face a essa formação, os gestores foram indagados sobre as dificuldades que enfrentaram no curso a distância mediante a plataforma PVANET, ${ }^{8}$ já que para utilizá-la é necessário um entendimento mínimo sobre tecnologia.

Com exceção de um profissional, os resultados mostraram que os gestores tiveram dificuldades em utilizar essa plataforma. Com isso, o uso das tecnologias ainda se apresenta como um desafio para muitos gestores e educadores no desenvolvimento do trabalho escolar. Esses profissionais de alguma forma estão sendo desafiados pelas transformações do mundo contemporâneo a adequar seu fazer pedagógico às tecnologias que o mercado consumidor gera. Contudo, cabe refletir se essas tecnologias, além de contribuírem para o processo ensino-aprendizagem, serão capazes de formar indivíduos reflexivos e críticos.

A reflexão sobre a Gestão Escolar Democrática foi outro ponto levantado. Como um dos princípios do curso é aflorar no profissional da gestão a importância do trabalho centra-

O PVANET é um ambiente virtual de aprendizado (AVA), desenvolvido e utilizado pela UFV para apoiar as disciplinas de cursos regulares, nas modalidades presenciais ou a distância, bem como, nos cursos de pósgraduação, na modalidade a distância. 
do na gestão democrática, questionou-se qual era a sua visão atual sobre essa questão após a participação no PNEGEB.

É perceptível nos registros a contribuição do curso na promoção da união do gestor e sua comunidade escolar. No entanto, chama a atenção o relato de um entrevistado que admite poder melhorar mais em relação à sua gestão. Esse é um sinal que por meio dessa formação o gestor passou a rever suas ações e, de algum modo, essa política pública educacional está surtindo efeitos e contribuindo para a sua prática profissional.

Segundo Cury (1997), a gestão pensada de forma democrática pode adquirir uma dimensão muito diferente daquela associada à ideia de comando. Isto significa que se pode administrar por meio do diálogo e do envolvimento do coletivo. Nessa perspectiva, o gestor deixa de ser o profissional que fiscaliza, controla e que centraliza em si as decisões, para ser, segundo Luck (2011), um mobilizador, um orquestrador de atores, um articulador da diversidade para dar unidade e consistência na construção do ambiente educacional e promoção segura da formação na escola.

Para finalizar, os gestores foram indagados se a formação no PNEGEB atendeu às expectativas em relação a essa formação continuada, ou seja, se contribuiu para uma possível mudança na prática pedagógica dos mesmos.

Em todos os enunciados os gestores afirmaram que tiveram mudanças significativas na sua prática pedagógica, após a realização do curso Escola de Gestores. Assim, os gestores participantes da pesquisa entenderam que essa formação e a prática reflexiva foram fundamentais para uma mudança e uma consequente melhoria da atuação profissional.

Nesse prisma nota-se, que a partir do que foi exposto por esses profissionais, a mudança na prática pedagógica está relacionada também a diferentes fatores que de modos distintos, influenciam esse processo. De um lado, estão as características pessoais de trabalho de cada um desses gestores e, de outro, o fato de serem propensos ou não a mudanças. Dessa maneira, pode-se constatar que a formação continuada deve pautar-se na reflexão do gestor acerca da sua prática, pois, segundo Freitas (2007), o trabalho formativo precisa incluir tanto o domínio teórico do conhecimento profissional quanto a capacidade de saber mobilizá-lo em situações concretas.

\section{CONSIDERAÇÕES FINAIS}

Este artigo teve como foco o PNEGEB na Universidade Federal de Viçosa-MG. Portanto, empenhou-se em pesquisar os problemas, as limitações e as contribuições dessa formação continuada para os gestores escolares.

No que concerne aos TCCs analisados dos cursistas do período de 2013-2014, destacou-se aqueles que abordaram temáticas relevantes que precisam ser colocadas em discussão no ambiente escolar. Percebeu-se, nessas análises, que os desafios escolares são muitos, porém, os olhares para essas situações problemas dentro do ambiente escolar não são tão diferentes. Por mais que as escolas estejam em espaços e contextos díspares, as abordagens das circunstâncias pelos gestores são sempre muito semelhantes.

62 Comunicações | Piracicaba | v. 24 | n. 3 | p. 51-65 | setembro-dezembro 2017 
Em relação aos questionários aplicados, compreendeu-se como ocorreu essa formação de gestores na instituição. Nesse interim, pode-se salientar que esses profissionais tiveram dificuldades com as tecnologias no começo do curso. Inicialmente, abordaram contratempos em compreender como funcionavam as salas ambientes, os fóruns e as postagens das atividades. No entanto, os mesmos demonstraram que estavam abertos às mudanças e que tentaram adequar-se às inovações tecnológicas.

Verificou-se também, em relação à gestão democrática, que muitas mudanças vêm ocorrendo e que todos gestores entenderam o real sentido do trabalho democrático. Somente um gestor, por mais que tenha compreendido esse processo, sentiu dificuldades em colocar em prática. Porém, não se pode ignorar que um dos maiores problemas encontrados no processo de gestão democrática está, principalmente, na transformação do pensamento daqueles que atuam nas instâncias superiores a ela.

Diante das reflexões explicitadas ao longo do artigo, torna-se relevante salientar sobre a questão do Projeto Político Pedagógico. Tal documento é o principal instrumento da gestão democrática no interior da escola e foi amplamente discutido nessa formação específica. Porém, entre o total de TCCs da última turma concluinte, esse foi o tema menos abordado pelos cursistas. Dois dos gestores respondentes do questionário não tinham muita apropriação desse documento. No entanto, afirmaram a respeito da importância dos conteúdos e das discussões disponibilizados pelo curso para um melhor entendimento sobre o assunto.

Nesse sentido, em muitos casos verificou-se que esse documento é copiado de outra escola ou é delegada a sua construção a uma única pessoa. Por isso, a formação continuada poderá ser um reforço para a aprendizagem e troca de experiências, podendo contribuir para a compreensão de várias situações problemas do ambiente escolar. Dessa forma, romper com o comodismo e a reprodução de um sistema que vigora há anos é uma decisão difícil e requer um alto nível de coragem e determinação desse profissional diante do novo.

Concluindo, pode-se afirmar, diante dos relatos dos gestores/cursistas, que esse processo de formação continuada foi relevante em sua essência diante da sua prática pedagógica e de suas condutas como gestores escolares. A formação continuada realizada a partir do PNEGEB na UFV-MG trouxe ganhos significativos no que tange à prática gestora, às discussões proporcionadas em relação aos desafios e dúvidas e, ao fortalecimento do trabalho coletivo. Talvez, o grande desafio da formação dos profissionais da educação na modalidade a distância não sejam somente as disparidades e diferenças regionais e, sim, a ampliação do debate acerca desse tipo de estudo e do entendimento que essa formação não acaba com o curso, esta necessita ser constante e contínua.

\section{REFERÊNCIAS}

AZEVEDO, S. de. Políticas públicas: discutindo modelos e alguns problemas de implementação. In: SANTOS JUNIOR, Orlando A. dos et al. Políticas públicas e gestão lo- 
cal: programa interdisciplinar de capacitação de conselheiros municipais. Rio de Janeiro: FASE, 2013.

BRASIL. Ministério da Educação. Escola de gestores da educação básica pública. Brasília, 2009.

CHAVES, S. D. Políticas Públicas de formação continuada de professores: a experiência do município de Itaguaí. Dissertação (Mestrado em Educação) - Universidade Estácio de Sá, 2012.

COSTA. C. J. Modelos de Educação Superior a Distância e Implementação da Universidade Aberta do Brasil. Revista Brasileira de Informática Educativa, v. 15, n. 2, 2007.

CURY, C. R. J. A nova lei de diretrizes e bases da educação nacional: Uma reforma educacional? In: Cury, C. R. J. et al. (Org.). Medo à liberdade e compromisso democrático: LDB e plano nacional de educação. São Paulo: Editora do Brasil, 1997.

DOMITE, M. C. C. Formação de professores e Etnomatemática: compreendendo para pedir mudanças. In: III SIPEM - Seminário Internacional de Pesquisas em Educação Matemática, Águas de Lindóia, 2006.

DOURADO, L. F. Políticas e gestão da educação superior a distância: novos marcos regulatórios? Educação \&. Sociedade, v. 29, n. 104, p. 891-917, out. 2008. Disponível em: $<$ http://www.scielo.br/pdf/es/v29n104/a1229104.pdf>. Acesso em: 21 fev. 2016.

FERNANDES, C. C. P. O Programa Nacional Escola de Gestores da Educação Básica e seus efeitos para a formação de Gestores escolares em Minas Gerais. Tese (Doutorado) - Universidade Federal de Juiz de Fora, Faculdade de Educação. Programa de Pós-Graduação em Educação, 2015.

FREITAS, H. C. L. A (nova) política de formação de professores: a prioridade postergada. Educação \& Sociedade. Campinas, v. 28, n. 100, Especial, p. 1.203-1.230, out. 2007.

GATTI, B. A. Formação de professores no Brasil: características e problemas. Educação e Sociedade. Campinas, v. 31, n. 113, p. 1.355-1.379, out./dez. 2010. Disponível em: $<$ http:// www.scielo.br/pdf/es/v31n113/16.pdf $>$. Acesso em: 20 out. 2015.

GOMES, R. Análise e interpretação de dados de pesquisa qualitativa. In: MINAYO, Maria Cecilia de Souza (Org.). Pesquisa social: teoria, método e criatividade, 32. ed. Petrópolis, RJ: Vozes, 2012.

LIBÂNEO, J. C. Organização e gestão da escola: teoria e prática, 5. ed. Goiânia: Alternativa, 2009.

LIMA, L. A escola como organização escolar. Ed. Cortez, 2001.

LUCK, H. Concepções e processos democráticos de gestão educacional. Petropólis, RJ: Ed. Vozes, 2011. 
LÜDKE, M.; ANDRÉ, M. Pesquisa em educação: abordagens qualitativas. São Paulo: EPU, 1986, 99 p.

MAINARDES, J.; FERREIRA, M. S.; TELLO, C. Análise de políticas: fundamentos e principais debates teórico-metodológicos. In: Ball, S. J.; Mainardes, J. (Org.). Políticas Educacionais: questões e dilemas, 1. ed. São Paulo: Cortez, 2011, p. 143-172.

MORAN. J. M. Os modelos educacionais na aprendizagem on-line. Disponível em: $<$ http://www.eca.usp.br/prof/moran/modelos.htm>. Acesso em: 16 set. 2015.

NÓVOA, A. (Org.). Vidas de professores, 2. ed. Porto: Porto, 2009.

PARO, V. H. Gestão democrática da escola pública. São Paulo: Ática, 2008.

TRIVINÕS, A. N. S. Introdução à pesquisa em ciências sociais: a pesquisa qualitativa em educação. São Paulo: Atlas, 1995.

VEIGA, I. P. A. (Org.). Projeto Político Pedagógico da escola: uma construção possível. Campinas, SP: Papirus, 2004.

\section{Dados dos AUTORES}

\section{Valdirene Eliane Bailon de Souza}

Mestre em Educação pela Universidade Federal de Viçosa. Professora do Programa de Apoio aos Dirigentes Municipais de Educação da Universidade Federal de Viçosa. Viçosa/ MG - Brasil.valdirene.souza@ufv.br

\section{Edgar Pereira Coelho}

Doutor em Educação/Filosofia da Educação pela Universidade de São Paulo. Professor no Programa de Pós-Graduação em Educação da Universidade Federal de Viçosa. Viçosa/MG - Brasil. edgar.coelho@ufv.br

\section{Rita Márcia Andrade Vaz de Mello}

Doutora em Educação pela Universidade Federal de Minas Gerais. Professora associada da Universidade Federal de Viçosa e Coordenadora de Cursos Lato Sensu. Viçosa/MG - Brasil. ritamarciamello@gmail.com

Submetido em: 31-7-2016

Aceito em: 26-10-2017 